\title{
Plump Kernels with High Deoxynivalenol Linked to Late Gibberella zeae Infection and Marginal Disease Conditions in Winter Wheat
}

\author{
Christina Cowger and Consuelo Arrellano
}

First author: U.S. Department of Agriculture-Agricultural Research Service, Department of Plant Pathology and second author: Department of Statistics, North Carolina State University, Raleigh 27695.

Accepted for publication 22 March 2010.

\begin{abstract}
Cowger, C., and Arrellano, C. 2010. Plump kernels with high deoxynivalenol linked to late Gibberella zeae infection and marginal disease conditions in winter wheat. Phytopathology 100:719-728.

Deoxynivalenol (DON) concentrations in mature wheat grain are usually correlated with symptoms produced by Gibberella zeae infection. However, there have been numerous observations of unacceptably high DON in asymptomatic crops, which can lead to lower-than-expected milling reductions in DON. We conducted a field experiment with winter wheat to examine the effect of infection timing and postanthesis moisture on grain quality and DON accumulation. Seven to eight soft red winter wheat cultivars were grown in three successive years in a misted nursery in Kinston, NC. Spikes were randomly selected for individual spray inoculation at 0 , 10, or 20 days after anthesis (daa). Starting at anthesis, plots were subjected to $0,10,20$, or 30 days of mist. Inoculated spikes and noninoculated controls were collected at harvest-ripeness, and the threshed grain was assayed for Fusarium-damaged kernels (FDK) and DON. In 2 of 3 years, percentages of FDK were significantly lower from
\end{abstract}

ABSTRACT 10-daa infections than from those at 0 daa, although DON concentrations were the same at the two inoculation timings in 2 of the 3 years. Those results indicate that the period of maximum susceptibility to wheat spike infections by G. zeae is close to or slightly less than 10 daa in North Carolina. In 2 of 3 years, FDK-DON correlation was greater for 0 - and 10-daa inoculations and for 0- to 20-daa misted treatments than for the later-inoculated or longer-misted treatments, respectively. The percentage of "low-FDK, high DON" (LFHD) observations (defined as FDK $\leq 4.0 \%$, DON $\left.\geq 2 \mu \mathrm{g} \mathrm{g}^{-1}\right)$ was higher in 2007 than in 2005 or $2006(41,14$, and $18 \%$, respectively). In both 2006 and 2007, high percentages of LFHD observations $(\geq 60 \%)$ occurred under marginal disease conditions involving late infection. We conclude that late infection is an important factor leading to LFHD grain. Periods of rain soon after anthesis likely favor the low-symptom, high-DON scenario, and conditions that create greater within-crop variability of anthesis timing may also be important.

Additional keywords: Fusarium graminearum, Fusarium head blight, scab, type I resistance, type II resistance.
Gibberella zeae (anamorph Fusarium graminearum) is the most important causal agent of Fusarium head blight (FHB, or scab) of wheat (Triticum aestivum) and barley (Hordeum vulgare) in the United States (13). FHB lowers grain yield and contaminates grain with mycotoxins such as deoxynivalenol (DON). In the United States, the Food and Drug Administration (FDA) has set $2 \mu \mathrm{g} \mathrm{g}^{-1}$ as the advisory ceiling for DON in wheat grain and $1 \mu \mathrm{g} \mathrm{g}^{-1}$ as the ceiling for DON in wheat flour (13).

DON levels in mature grain are usually correlated with visible disease $(16,23)$; however, there have been numerous observations of high DON in relatively asymptomatic crops $(5,6,27,30)$. The conditions that give rise to the scenario of plump, healthyappearing grain with excessive DON levels are not well understood. This phenomenon has created problems for the U.S. milling and baking industry (22), in part because anticipated reductions in DON associated with the milling of wheat into flour are not realized.

With FHB of wheat, the timing of infection is known to be important in determining disease occurrence. Francl et al. (7) indicated that release of G. zeae ascospores, which are thought to be the principal cause of primary infections, can occur throughout

Corresponding author: C. Cowger;

E-mail address: Christina.Cowger@ars.usda.gov

doi:10.1094/PHYTO-100-7-0719

This article is in the public domain and not copyrightable. It may be freely reprinted with customary crediting of the source. The American Phytopathological Society, 2010. the grain-fill period, with inoculum most abundant following multiple-day rainy periods. Extruded wheat anthers are thought to be the primary FHB infection site (21). It has been suggested that anther infections result in lack of kernel development, whereas later infections can lead to shriveled DON-containing kernels and still-later infections to healthy-appearing kernels that contain DON (25); however, experimental evidence is lacking.

Investigations of FHB infection timing suggest that, although the period of maximum host susceptibility generally starts at anthesis, this may be cultivar dependent, and the duration of the susceptibility period may depend on environmental conditions. One of the earliest controlled studies was by Schroeder and Christensen (26), who inoculated seven spring wheat cultivars in a greenhouse at anthesis, milk, and soft dough stages with both spray and single-spikelet injection. The authors concluded that degree of resistance to both initial infection (type I resistance) and to spread within the spike after infection (type II resistance) depended on infection timing (i.e., some cultivars were more susceptible at anthesis while others reached a maximum of susceptibility at milk or at soft dough). Schroeder and Christensen (26) recorded disease symptoms and percentages of damaged and infected kernels but did not measure DON.

Three later studies of FHB-causing Fusarium spp. examined the effects of infection timing on both disease and DON levels in wheat spikes. Hart et al. (9) sprayed F. graminearum spores on spikes of a single cultivar in a greenhouse and seven winter wheat cultivars in a field experiment. Inoculation timings in the field ranged from early milk to mid-dough stage, and spikes were bagged for varying periods of time following inoculation. DON 
production depended on hours of head wetness, not on kernel development at the time of artificial inoculation. Later infections in field-grown wheat resulted in some DON development but with less yield loss. Using multiple Fusarium spp., Lacey et al. (12) varied the timing of infection of winter wheat cv. Hussar from early heading to soft dough. Anthesis was the only infection timing to produce high DON concentrations $\left(\approx 12 \mu \mathrm{g} \mathrm{g}^{-1}\right)$ in mature grain. In one year, Lacey et al. (12) also observed a significant interaction between infection timing and postinoculation moisture duration, such that DON levels from mid-anthesis infections rose more sharply with increasing postinoculation moisture durations than did DON levels associated with other infection timings. In a controlled-environment study with $F$. graminearum, Del Ponte et al. (6) spray inoculated spikes of a single susceptible spring wheat cultivar at each of six stages from anthesis to hard dough. DON values were highest in spikes inoculated at the kernel watery-ripe and early milk stages. Fusariumdamaged kernels (FDK) comprised 94 to $100 \%$ of samples with inoculation timings from mid-anthesis to late milk but fell to $23 \%$ for inoculation at hard dough. DON concentrations for the highest levels of FDK (90 to $100 \%$ ) varied widely (20 to $120 \mu \mathrm{g} \mathrm{g}^{-1}$ ), with the highest concentrations found in high-FDK samples inoculated at the watery-ripe and early milk stages. Del Ponte et al. (6) suggested that plump, high-yielding wheat could contain DON $>2 \mu \mathrm{g} \mathrm{g}^{-1}$ because infection late in kernel development might produce DON without significant shriveling or grain weight reduction.

In summary, it has been suggested that late (post-anthesis) infections can result in problematic harvest-time DON levels without the same degree of kernel shriveling and lowered yield as infections that occur at anthesis. Empirical validation has been lacking, particularly using multiple cultivars and manipulating moisture regimes in field conditions. In this study, our goal was to better understand the effect of infection timing and post-anthesis moisture on grain quality and DON accumulation in wheat and, specifically, to shed light on the conditions that lead to the "low FDK, high-DON" (LFHD) scenario. Based on the literature described above, we hypothesized that post-anthesis infections would lead to lower correlation between FDK and DON, with higher DON levels than might be expected based on the percentage of FDK, but the effect of late infections would vary according to moisture duration.

\section{MATERIALS AND METHODS}

Field experiment location and design. A field experiment was conducted in a misted nursery at the Cunningham Research and
Extension Center in Kinston, NC. The experiment was conducted simultaneously to that described by Cowger et al. (3) but using separate plots. Essentially the same experiment was performed in each of three field seasons-2004-05, 2005-06, and 2006-07hereafter referred to as 2005,2006 , and 2007, respectively. In each year, the experiment was planted in a conventionally tilled field (full primary and secondary tillage with burying of crop residues) following corn or soybean.

The experiment had one block each for misting durations of 0 , 10, 20, and 30 days after anthesis (daa). Within each block, there were three replicate subblocks. Within each subblock, cultivars were randomly assigned to subplots, such that three replicate subplots of each cultivar were subjected to each duration of postanthesis misting. Subplots were planted with a five-row plot drill. After trimming subplot ends for evenness of length, each subplot measured $3.1 \mathrm{~m}$ in length and $1.2 \mathrm{~m}$ in width.

Cultivars for the experiment (Table 1) were chosen from among regionally adapted lines with similar maturities and a range of putative resistance types (type I, resistance to primary infection; type II, resistance to subsequent colonization; or both) (14). For the moderately resistant cultivars, resistance types were postulated based on incidence, severity, and DON data from the 20002003 Uniform Southern Soft Red Winter Wheat FHB Screening Nurseries (17-20). As an approximate indicator of resistance type, a high incidence/severity ratio was taken as evidence of type II resistance and, conversely, a high severity/incidence ratio as evidence of type I resistance. Cultivars had appeared in the uniform nursery for varying numbers of years. VA01W-99 was an elite line with pedigree FFR525/93-52-55 (Massey*3/Balkan// Saluda) that had shown a high level of FHB resistance in field experiments (J. Chen and C. Griffey, personal communication).

Inoculation and misting. To generate inoculum for the field experiment, four isolates of $F$. graminearum with proven pathogenicity to wheat (data not shown) were increased individually in aerated 20-liter carboys of Mung bean tea. The tea was prepared by steeping Mung beans in boiled $\mathrm{dH}_{2} \mathrm{O}$ at a rate of $40 \mathrm{~g} \mathrm{liter}^{-1}$ for 15 min, filtering the tea through cheesecloth, and autoclaving. Carboys containing 12 liters of tea were spiked with $500 \mathrm{ml}$ of tea in which macroconidia had been previously grown, and then aerated with sterile air for $\approx 1$ week before centrifugation of the broth at 4,000 rpm for 3 min to collect macroconidia.

Inoculations were performed at 0,10 , or 20 days after midanthesis (hereafter designated 0,10 , or 20 daa). The 10-daa and 20-daa inoculation timings were at watery-ripe (Zadoks 71) and late-milk (Zadoks 77) growth stages, respectively. Prior to inoculation, 40 spikes per plot were selected arbitrarily for each inocu-

TABLE 1. Soft red winter wheat cultivars planted in Kinston, NC, field experiment to determine the effects of late infection and post-flowering moisture on Fusarium head blight (FHB) severity and deoxynivalenol (DON) accumulation

\begin{tabular}{|c|c|c|c|c|c|c|c|c|}
\hline \multirow[b]{3}{*}{ Cultivar } & \multirow[b]{3}{*}{ P.I. or PVPu } & \multirow[b]{3}{*}{ Heading $^{v}$} & \multirow[b]{3}{*}{$\mathrm{FHB}^{\mathrm{w}}$} & \multirow[b]{3}{*}{ Type $^{\mathrm{x}}$} & \multicolumn{4}{|c|}{ Inoculated at anthesis, no misting ${ }^{y}$} \\
\hline & & & & & \multicolumn{2}{|c|}{2006} & \multicolumn{2}{|c|}{2007} \\
\hline & & & & & DON $\left(\mu \mathrm{g} \mathrm{g}^{-1}\right)$ & $\operatorname{FDK}(\%)$ & DON $\left(\mu \mathrm{g} \mathrm{g}^{-1}\right)$ & FDK $(\%)$ \\
\hline NC-Neuse & 200400303 & 115 & MR & Type II & 6.5 & 5.7 & 4.5 & 2.3 \\
\hline Ernie & 9600360 & 109 & MR & Type I & 5.7 & 2.3 & 3.3 & 3.3 \\
\hline VA01W-99 & Experimental & 111 & MR & Type II & 5.5 & 9.3 & 1.1 & 0.7 \\
\hline V-Tribute ${ }^{z}$ & 632689 & 112 & MR & Type I & 5.8 & 8.0 & $\ldots$ & $\ldots$ \\
\hline USG 3592 & 200400110 & 112 & $\mathrm{~S}$ & Susceptible & 14.7 & 19.3 & 5.8 & 6.7 \\
\hline Mean & $\ldots$ & $\ldots$ & $\ldots$ & $\ldots$ & 7.8 & 7.5 & 3.5 & 2.3 \\
\hline
\end{tabular}

" P.I. = Plant introduction number and PVP = Plant Variety Protection.

${ }^{v}$ Heading date (day of year), based on 2005 data from the Cunningham Research Station OVT and unpublished data.

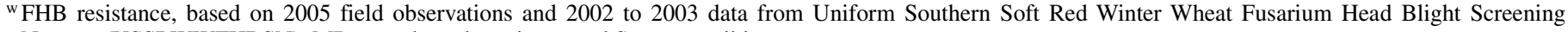

Nursery (USSRWWFHBSN). MR = moderately resistant and $\mathrm{S}=$ susceptible.

x Putative resistance type, based on incidence: severity ratio from 2000 to 2003 USSRWWFHBSN data, except VA01W-99; see text.

y Inoculation using a $10^{5}$ macroconidia $\mathrm{ml}^{-1}$ suspension with a spray bottle on individual spikes. FDK $=$ Fusarium-damaged kernels.

z Vigoro Tribute only planted in 2006. 
lation timing and marked by placing tape of a color specific to that timing around the stem below the peduncle. In order to reduce edge effects, spikes were not chosen from exterior rows or the $0.3 \mathrm{~m}$ at each end of each plot. Mid-anthesis was considered to be the day on which $50 \%$ of the heads of a given cultivar had extruded anthers; thus, for each particular inoculation (e.g., 10 daa), cultivars might be inoculated on different dates. The dates of inoculation were 22 to 29 April 2005, 13 to 19 April 2006, and 17 to 25 April 2007. In 2007, the variability of anthesis timing was increased by an epidemic of Wheat soilborne mosaic virus, which had a patchy distribution and caused mild stunting and delayed anthesis in some plots.

For inoculation of the spikes, a suspension of $10^{4}$ macroconidia $\mathrm{ml}^{-1}$ was used in 2005; the concentration was raised to $10^{5}$ macroconidia $\mathrm{ml}^{-1}$ in 2006 and 2007 in order to increase disease severity. The suspension was composed of equal proportions of spores of the four isolates. A wide-necked plastic funnel was placed over each spike to be inoculated, such that the spike was surrounded and shielded from nearby spikes by the flaring part of the funnel. Three squirts of the inoculum suspension were delivered to the spike from a spray bottle that was frequently shaken between spikes.

Post-anthesis misting was provided using Roberts 435/436 mist nozzles (Mid-Atlantic Irrigation, Farmville, VA), which have small-diameter (1.4-mm) orifices, mounted on risers at a height of $0.91 \mathrm{~m}$ above the ground. The different durations of post-anthesis mist were provided by opening or closing individual lateral irrigation lines. By means of a programmable timer, mist was provided for 2 min during each 20-min period for $3 \mathrm{~h}$ each in the morning and afternoon (8:00 to 11:00 a.m. and 2:00 to 5:00 p.m.), for a total of $36 \mathrm{~min}$ per day. Taking sprinkler overlap into account, actual flow delivered was $0.275 \mathrm{~mm} \mathrm{~min}^{-1}$. All periods of post-anthesis mist $(0,10,20$, or 30 daa) started in the middle of the inoculation period (on 28 April 2005, 17 April 2006, and 23 April 2007).

Due to limited misted nursery space, buffer plots could not be planted between all treatments. However, buffer strips of the moderately resistant cv. NC-Neuse were planted to avoid interference of irrigation treatments, and borders of NC-Neuse were planted around the experiment.

Collection and assays of samples. The tape-labeled spikes were hand harvested soon after harvest ripeness (13 June 2005, 9 June 2006, and 7 June 2007). Spikes were bulked by inoculation date and plot, and threshed in a single-head thresher (Precision Machine, Lincoln, NE), such that all kernels were retained. To determine the percentage of FDK, 100 kernels were selected arbitrarily for each inoculation timing in each plot and visually inspected for gray-white or pink discoloration and mycelial growth. Grain was assayed for DON content using enzyme-linked immunosorbent assay analysis at the Regional Diagnostic Clinic for Fusarium Head Blight at Michigan State University in 2005 and 2006, and by Dr. Yanhong Dong at the University of Minnesota using gas chromatography-mass spectrometry in 2007.

In 2007, the percentage of infected kernels was determined by surface-sterilizing 25 randomly chosen kernels per sample for $2 \mathrm{~min}$ in $5 \%$ bleach, and plating the kernels on Komada's selective medium (11). Kernels were incubated for 7 days in a growth chamber at $22^{\circ} \mathrm{C}$ on a 12-h light-and-dark cycle. Infected kernels were identified from fluffy, peach-white mycelial growth and characteristic discoloration of the medium beneath the kernels. Where necessary, spore morphology was determined microscopically to confirm infection by $F$. graminearum.

2008 data. When results for the 10-daa inoculation treatment differed among the 3 years (as reported below), data were also analyzed for a similar field experiment conducted the following year (2007-08) in order to strengthen the interpretation of the 0 -daa versus 10-daa inoculation comparison. Although the 2008 experiment was designed to address different questions, it also included the 0- and 10-daa inoculation timings, and those data are relevant to the present report. The experimental protocol was the same except as follows: the moderately resistant cv. Roane replaced USG 3650, for which seed could no longer be obtained; plots consisted of two adjacent 1.22-m rows; the misting treatments were $0,7,14$, and 21 daa; inoculations were conducted with a backpack sprayer instead of a spray bottle; there was no 20-daa inoculation; and there were four replicates instead of three.

Statistical analysis. To determine the effects of the independent experimental factors on FDK and DON, a general linear mixed model was fitted to data using the MIXED procedure in SAS (version 9.1.3; SAS Institute, Cary, NC). Fixed effects were inoculation timing, misting duration, cultivar, and year. Replicate was treated as a random effect. Data were subject to square-root transformation before analysis. Inspection of residual plots indicated the need for square-root transformation of FDK and DON data to attain normality and homogeneity of variances. The restricted maximum likelihood method was used to calculate variance components in the mixed model. A Satterthwaite-type adjustment was applied to account for unequal numbers of repetitions and zero-covariance estimates in the estimation of standard errors and $F$ tests for fixed effects.

Least-squares means separation was performed using Tukey's test and the pdmix800.sas macro (24). Analysis of variance showed a significant year-to-year difference in samples inoculated 10 daa (year-inoculation date had $P<0.0001$; data not shown); therefore, the data from each year were analyzed separately. Mixed-effects models for 2005, 2006, and 2007 modeled a separate residual variance for each level of inoculation timing, whereas in 2008 a common residual variance was modeled.

To address the conditions leading to grain with low FDK and excessive DON concentrations, we identified "low FDK, highDON" (LFHD) observations and determined their frequency for different treatments. We assigned an LFHD score of 1 if an observation had a DON concentration $\geq 2.0 \mu \mathrm{g} \mathrm{g} \mathrm{g}^{-1}$ and FDK $\leq$ $4.0 \%$. The DON threshold was set at $2.0 \mu \mathrm{g} \mathrm{g}^{-1}$ to correspond to the FDA-recommended threshold for DON in wheat grain. Beyer et al. (1) found that, on average, $4.3 \%$ FDK was equivalent to $1.25 \mu \mathrm{g} \mathrm{g}^{-1}$ of DON, which supports the choice of $4 \%$ FDK as an upper limit for "low FDK." Observations that did not meet the criteria of DON $\geq 2.0 \mu \mathrm{g} \mathrm{g}^{-1}$ and FDK $\leq 4.0 \%$ received a score of 0 . The noninoculated observations were excluded from this analysis.

Because, in both 2005 and 2006, there were several combinations of mist duration and inoculation date for which there were no LFHD observations, the SAS procedure GLIMMIX could not be used for 2005 and 2006 samples as it was for 2007 samples (below). Instead, and for all 3 years, the SAS MEANS procedure was used to determine the Agresti-Coull or adjusted WALD 95\% confidence limits for observed proportions of LFHD within each experimental group (inoculation-mist duration combination). In 2007, however, the LFHD scores were more variable at all levels of inoculation and misting and, thus, the SAS procedure GLIMMIX was also used to model the probability that the LFHD score was $1\left(p_{\text {LFHD }}=1\right)$ with a generalized linear model that included logit of $p_{\mathrm{LFHD}}, \log \left(p_{\mathrm{LFHD}} /\left[1-p_{\mathrm{LFHD}}\right]\right)$ as the response variable; the main effects of mist duration and inoculation date and their interaction as fixed effects; and cultivar as a randomeffect factor.

In order to analyze how the relationship between FDK and DON changed across different levels of the experimental factors of misting duration, inoculation, and their interactions, residuals from the general mixed model described above (fitted to FDK and DON separately) were used to calculate Pearson correlations and their $95 \%$ confidence intervals. Pairwise comparisons were conducted on the $z$-transformed values (29) for proportions of interest. 


\section{RESULTS}

Infection timing effects on FDK and DON. In 2005, 2006, and 2007, significant differences in FDK and DON were associated with different inoculation timings (Table 2), and there were also significant interactions between inoculation timing and the factors of mist duration and cultivar in both years. The significant interaction of mist duration and inoculation timing was due to magnitude differences (differences in line slope) rather than rank- ing changes except for FDK in 2007, where the effect of changing from 0 - to 10-daa inoculation was different for the 0- and 10-daa misted treatments than for the 20- and 30-daa misted treatments (Table 3).

In 2005 and 2006, there was significantly more FDK in spikes inoculated at anthesis than at any other time, whereas in 2007 percentages of FDK were the same for spikes inoculated at 0 or 10 daa (Table 3 ). In other words, inoculations at 10 daa produced different results in the 3 years: in 2005, 10-daa FDK levels were

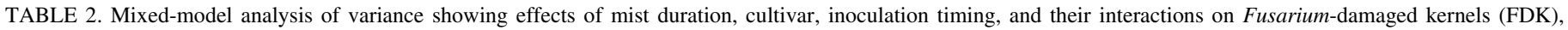
deoxynivalenol (DON), and percent infected kernels in a field experiment with Fusarium head blight conducted in 2005, 2006, and 2007 at Kinston, NC

\begin{tabular}{|c|c|c|c|c|c|c|c|c|c|c|c|c|c|c|c|c|c|}
\hline \multirow[b]{3}{*}{ Effect } & \multicolumn{5}{|c|}{2005} & \multicolumn{5}{|c|}{2006} & \multicolumn{7}{|c|}{2007} \\
\hline & \multirow[b]{2}{*}{$\mathrm{df}$} & \multicolumn{2}{|c|}{ FDK } & \multicolumn{2}{|c|}{ DON } & \multirow[b]{2}{*}{$\mathrm{df}$} & \multicolumn{2}{|c|}{ FDK } & \multicolumn{2}{|c|}{ DON } & \multirow[b]{2}{*}{$\mathrm{df}$} & \multicolumn{2}{|c|}{ FDK } & \multicolumn{2}{|c|}{ DON } & \multicolumn{2}{|c|}{$\operatorname{Inf}(\%)^{\mathrm{w}}$} \\
\hline & & $F$ & $P$ & $F$ & $P$ & & $F$ & $P$ & $F$ & $P$ & & $F$ & $P$ & $F$ & $P$ & $F$ & $P$ \\
\hline \multicolumn{18}{|l|}{ Fixed effects } \\
\hline Mist $(M)^{x}$ & 3 & 0.6 & 0.65 & 1.5 & 0.23 & 3 & 23.1 & $<0.0001$ & 45.7 & $<0.0001$ & 3 & 8.9 & 0.01 & 17.1 & 0.0007 & 8.4 & 0.01 \\
\hline Cultivar (C) $)^{\mathrm{y}}$ & 6 & 18.1 & $<0.0001$ & 29.0 & $<0.0001$ & 7 & 6.4 & $<0.0001$ & 20.7 & $<0.0001$ & 6 & 10.3 & $<0.0001$ & 54.6 & $<0.0001$ & 6.6 & $<0.0001$ \\
\hline $\mathrm{M} \times \mathrm{C}$ & 18 & 1.8 & 0.03 & 0.7 & 0.77 & 21 & 1.1 & 0.35 & 2.2 & 0.005 & 18 & 1.6 & 0.11 & 1.6 & 0.11 & 1.7 & 0.04 \\
\hline Inoc date $(\mathrm{I})^{\mathrm{z}}$ & 2 & 120.8 & $<0.0001$ & 223.6 & $<0.0001$ & 2 & 316.3 & $<0.00011$ & 397.2 & $<0.0001$ & 2 & 27.7 & $<0.0001$ & 193.2 & $<0.0001$ & 1.0 & 0.39 \\
\hline $\mathrm{M} \times \mathrm{I}$ & 6 & 5.7 & $<0.0001$ & 4.0 & 0.001 & 6 & 10.8 & $<0.0001$ & 17.8 & $<0.0001$ & 6 & 7.6 & $<0.0001$ & 4.0 & 0.0003 & 2.6 & 0.02 \\
\hline $\mathrm{C} \times \mathrm{I}$ & 12 & 13.4 & $<0.0001$ & 16.1 & $<0.0001$ & 14 & 2.3 & 0.01 & 11.3 & $<0.0001$ & 12 & 3.9 & $<0.0001$ & 19.2 & $<0.0001$ & 1.3 & 0.22 \\
\hline $\mathrm{M} \times \mathrm{C} \times \mathrm{I}$ & 36 & 1.0 & 0.52 & 1.3 & 0.18 & 42 & 1.5 & 0.05 & 2.0 & 0.003 & 36 & 1.1 & 0.39 & 2.5 & 0.0001 & 1.5 & 0.07 \\
\hline \multicolumn{18}{|l|}{ Random effects } \\
\hline $\operatorname{Rep}(\mathrm{M})$ & $\ldots$ & $\ldots$ & 0.0002 & $\ldots$ & 0.0002 & $\ldots$ & $\ldots$ & 0.0 & $\ldots$ & 0.005 & $\ldots$ & $\ldots$ & 0.0006 & $\ldots$ & 0.02 & $\ldots$ & $\ldots$ \\
\hline $\operatorname{Rep} \times C(M)$ & $\ldots$ & $\ldots$ & 0.0 & $\ldots$ & 0.0 & $\ldots$ & $\ldots$ & 0.0 & $\ldots$ & 0.007 & $\ldots$ & $\ldots$ & 0.0004 & $\ldots$ & 0.05 & $\ldots$ & $\ldots$ \\
\hline Resid.(I = 0 daa) & $\ldots$ & $\ldots$ & 0.007 & $\ldots$ & 0.29 & $\ldots$ & $\ldots$ & 0.01 & $\ldots$ & 0.28 & $\ldots$ & $\ldots$ & 0.01 & $\ldots$ & 0.18 & $\ldots$ & $\ldots$ \\
\hline Resid.(I = 10 daa $)$ & $\ldots$ & $\ldots$ & 0.005 & $\ldots$ & 0.45 & $\ldots$ & $\ldots$ & 0.0003 & $\ldots$ & 0.04 & $\ldots$ & $\ldots$ & 0.007 & $\ldots$ & 0.13 & $\ldots$ & $\ldots$ \\
\hline Resid.(I = 20 daa $)$ & $\ldots$ & $\ldots$ & 0.002 & $\ldots$ & 0.06 & $\ldots$ & $\ldots$ & 0.002 & $\ldots$ & 0.03 & $\ldots$ & $\ldots$ & 0.004 & $\ldots$ & 0.03 & $\ldots$ & $\ldots$ \\
\hline
\end{tabular}

${ }^{v}$ All $F$ and $P$ values are from analysis of variance using square-root-transformed data to increase homoscedasticity of variances.

w Infected kernels.

${ }^{x}$ Plots were misted $0,10,20$, or 30 days after anthesis (daa).

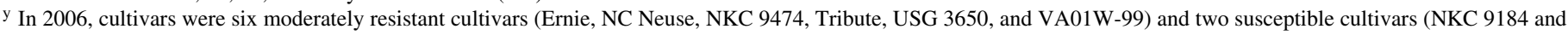
USG 3592). Tribute was not planted in 2007.

${ }^{\mathrm{z}}$ Inoculation (Inoc) dates were 0, 10 (watery-ripe), and 20 (late milk) daa; noninoculated samples were excluded from this analysis.

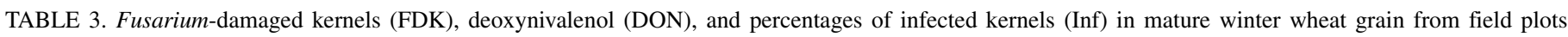
inoculated at different time points and subjected to different durations of post-anthesis misting in 3 years at Kinston, NC ${ }^{\mathrm{x}}$

\begin{tabular}{|c|c|c|c|c|c|c|c|c|c|c|c|c|}
\hline \multirow[b]{3}{*}{ Mist (days) ${ }^{\mathrm{y}}$} & \multicolumn{9}{|c|}{ Inoculation date (days after anthesis) ${ }^{\mathrm{z}}$} & & & \\
\hline & \multicolumn{3}{|c|}{0} & \multicolumn{3}{|c|}{10} & \multicolumn{3}{|c|}{20} & \multicolumn{3}{|c|}{ Noninoculated } \\
\hline & FDK $(\%)$ & $\operatorname{DON}\left(\mu \mathrm{g} \mathrm{g}^{-1}\right)$ & $\operatorname{Inf}(\%)$ & FDK $(\%)$ & $\operatorname{DON}\left(\mu \mathrm{g} \mathrm{g}^{-1}\right)$ & $\operatorname{Inf}(\%)$ & FDK $(\%)$ & $\mathrm{DON}\left(\mu \mathrm{g} \mathrm{g}^{-1}\right)$ & $\operatorname{Inf}(\%)$ & FDK $(\%)$ & $\mathrm{DON}\left(\mu \mathrm{g} \mathrm{g}^{-1}\right)$ & $\operatorname{Inf}(\%)$ \\
\hline \multicolumn{13}{|l|}{2005} \\
\hline 0 & $5.1 \mathrm{a}$ & $2.1 \mathrm{a}$ & $\ldots$ & $2.5 \mathrm{a}$ & $1.9 \mathrm{a}$ & $\ldots$ & $0.6 \mathrm{a}$ & $0.1 \mathrm{a}$ & $\ldots$ & $0.1 \mathrm{a}$ & $0.0 \mathrm{a}$ & $\ldots$ \\
\hline 10 & $4.9 \mathrm{ab}$ & $3.6 \mathrm{a}$ & $\ldots$ & $1.0 \mathrm{a}$ & $1.6 \mathrm{a}$ & $\ldots$ & $0.4 \mathrm{a}$ & $0.1 \mathrm{a}$ & $\ldots$ & $0.4 \mathrm{a}$ & $0.1 \mathrm{a}$ & $\ldots$ \\
\hline 20 & $3.7 \mathrm{ab}$ & $2.0 \mathrm{a}$ & $\ldots$ & $4.7 \mathrm{a}$ & $4.1 \mathrm{a}$ & $\ldots$ & $0.2 \mathrm{a}$ & $0.0 \mathrm{a}$ & $\ldots$ & $0.2 \mathrm{a}$ & $0.2 \mathrm{a}$ & $\ldots$ \\
\hline 30 & $3.1 \mathrm{~b}$ & $2.3 \mathrm{a}$ & $\ldots$ & $3.7 \mathrm{a}$ & $2.5 \mathrm{a}$ & $\ldots$ & $0.1 \mathrm{a}$ & $0.2 \mathrm{a}$ & $\ldots$ & $0.1 \mathrm{a}$ & $0.0 \mathrm{a}$ & $\ldots$ \\
\hline Mean & $4.2 \mathrm{~A}$ & $2.5 \mathrm{~A}$ & $\ldots$ & $3.0 \mathrm{~B}$ & $2.5 \mathrm{~A}$ & $\ldots$ & $0.3 \mathrm{C}$ & $0.1 \mathrm{~B}$ & $\ldots$ & $0.1 \mathrm{D}$ & $0.1 \mathrm{~B}$ & $\ldots$ \\
\hline \multicolumn{13}{|l|}{2006} \\
\hline 0 & $7.5 \mathrm{a}$ & $7.8 \mathrm{a}$ & $\ldots$ & $0.2 \mathrm{a}$ & $0.6 \mathrm{a}$ & $\ldots$ & $0.4 \mathrm{a}$ & $0.2 \mathrm{a}$ & $\ldots$ & $0.3 \mathrm{a}$ & $0.2 \mathrm{a}$ & $\ldots$ \\
\hline 10 & $8.9 \mathrm{a}$ & $13.3 \mathrm{~b}$ & $\ldots$ & $0.1 \mathrm{a}$ & $1.2 \mathrm{~b}$ & $\ldots$ & $0.1 \mathrm{a}$ & $0.5 \mathrm{ab}$ & $\ldots$ & $1.0 \mathrm{ab}$ & $0.6 \mathrm{~b}$ & $\ldots$ \\
\hline 20 & $17.9 \mathrm{c}$ & $16.7 \mathrm{c}$ & $\ldots$ & $1.2 \mathrm{~b}$ & $2.4 \mathrm{c}$ & $\ldots$ & $0.1 \mathrm{a}$ & $0.5 \mathrm{ab}$ & $\ldots$ & $1.0 \mathrm{ab}$ & $0.7 \mathrm{~b}$ & $\ldots$ \\
\hline 30 & $11.3 \mathrm{~b}$ & $15.6 \mathrm{c}$ & $\ldots$ & $1.7 \mathrm{~b}$ & $3.0 \mathrm{c}$ & $\ldots$ & $0.5 \mathrm{a}$ & $0.8 \mathrm{~b}$ & $\ldots$ & $1.5 \mathrm{~b}$ & $1.3 \mathrm{c}$ & $\ldots$ \\
\hline Mean & $11.4 \mathrm{~A}$ & $13.9 \mathrm{~A}$ & $\ldots$ & $0.8 \mathrm{~B}$ & $1.9 \mathrm{~B}$ & $\ldots$ & $0.3 \mathrm{C}$ & $0.5 \mathrm{C}$ & $\ldots$ & $1.0 \mathrm{~B}$ & $0.7 \mathrm{C}$ & $\ldots$ \\
\hline \multicolumn{13}{|l|}{2007} \\
\hline 0 & $2.3 \mathrm{a}$ & $3.5 \mathrm{a}$ & $4.8 \mathrm{a}$ & $5.8 \mathrm{a}$ & $4.9 \mathrm{a}$ & $5.9 \mathrm{a}$ & $1.4 \mathrm{a}$ & $1.6 \mathrm{a}$ & $6.9 \mathrm{a}$ & $0.5 \mathrm{a}$ & $1.0 \mathrm{a}$ & $1.1 \mathrm{a}$ \\
\hline 10 & $4.7 \mathrm{ab}$ & $6.3 \mathrm{~b}$ & $9.1 \mathrm{ab}$ & $2.1 \mathrm{~b}$ & $5.6 \mathrm{a}$ & $7.7 \mathrm{a}$ & $2.0 \mathrm{a}$ & $1.8 \mathrm{a}$ & $7.2 \mathrm{ab}$ & $1.7 \mathrm{ab}$ & $1.4 \mathrm{a}$ & $6.9 \mathrm{~b}$ \\
\hline 20 & $11.5 \mathrm{c}$ & $10.9 \mathrm{c}$ & $13.5 \mathrm{~b}$ & $8.7 \mathrm{a}$ & $9.3 \mathrm{c}$ & $17.7 \mathrm{~b}$ & $2.2 \mathrm{a}$ & $3.8 \mathrm{~b}$ & $8.4 \mathrm{ab}$ & $2.5 \mathrm{~b}$ & $3.2 \mathrm{~b}$ & $3.4 \mathrm{a}$ \\
\hline 30 & $5.7 \mathrm{~b}$ & $7.3 \mathrm{~b}$ & $14.9 \mathrm{~b}$ & $7.2 \mathrm{a}$ & $8.1 \mathrm{~b}$ & $15.2 \mathrm{~b}$ & $2.0 \mathrm{a}$ & $3.4 \mathrm{~b}$ & $14.9 \mathrm{~b}$ & $2.0 \mathrm{ab}$ & $2.2 \mathrm{ab}$ & $4.0 \mathrm{a}$ \\
\hline Mean & $6.0 \mathrm{~A}$ & $7.0 \mathrm{~A}$ & $10.6 \mathrm{~A}$ & $5.9 \mathrm{~A}$ & $7.0 \mathrm{~A}$ & $11.6 \mathrm{~A}$ & $1.9 \mathrm{~B}$ & $2.7 \mathrm{~B}$ & $9.3 \mathrm{~A}$ & $1.7 \mathrm{~B}$ & $1.9 \mathrm{C}$ & $3.9 \mathrm{~B}$ \\
\hline \multicolumn{13}{|l|}{2008} \\
\hline Mean & $6.8 \mathrm{~A}$ & $2.9 \mathrm{~A}$ & $\ldots$ & $3.9 \mathrm{~B}$ & $1.6 \mathrm{C}$ & $\ldots$ & $\ldots$ & $\ldots$ & $\ldots$ & $\ldots$ & $\ldots$ & $\ldots$ \\
\hline
\end{tabular}

${ }^{x}$ In 2006 and 2007, individual spikes were inoculated with a spray bottle whereas, in 2008, two-row plots were inoculated with a backpack sprayer.

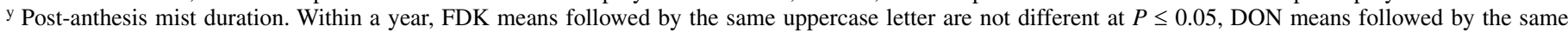
uppercase letter are not different at $P \leq 0.05$, and percent infected kernels means followed by the same uppercase letter are not different at $P \leq 0.05$ by leastsquares means.

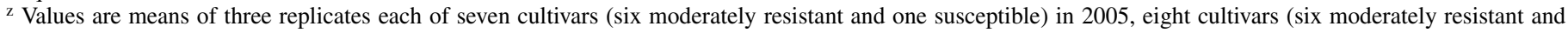
two susceptible) in 2006, seven cultivars (five moderately resistant and two susceptible) in 2007, and eight cultivars (six moderately resistant and two susceptible) in 2008. Five cultivars were common to all 4 years. To improve homoscedasticity, means were separated using square-root transformed data in all cases except percent infected seed in 2008, where the best fit was with untransformed data. Within a year and column, values followed by the same small letter are not different at $P \leq 0.05$ by least-squares means; 10 -daa $=$ watery-ripe; 20 -daa $=$ late milk. 
intermediate between 0-daa and 20-daa levels; in 2006, 10-daa levels were the same as those in noninoculated samples (i.e., background levels); and, in 2007, 10-daa FDK levels were the same as 0-daa levels and significantly higher than 20-daa or background levels. One factor in the wider period of susceptibility in 2007 was likely the occurrence of Wheat soilborne mosaic virus (SBWMV). The mild and patchy stunting caused by SBWMV delayed flowering in some plots and contributed to greater variability in anthesis timing within each plot. Cold temperatures on several nights in early April 2007 may also have contributed to the variability.

Trends with DON were similar to those with FDK (Tables 2 and 3). Inoculations at 20 daa produced mean DON levels no different from the background levels of DON in noninoculated spikes (2005 and 2006) or slightly higher (2007) (Table 3). Inoculations at anthesis produced significantly higher DON levels than 20-daa inoculations, whereas 10-daa inoculations resulted in DON levels lower than those from 0-daa inoculations in 2006 but the same as those from 0-daa inoculations in 2005 and 2007.

Because the 10-daa result was variable for both FDK and DON during 2005 to 2007, results of late inoculation in 2008 were also considered as a fourth year of data on this specific question (Table 3 ), although the misting durations were different from those in the previous 3 years. In 2008, FDK and DON levels were significantly lower from 10-daa inoculation than from inoculation at anthesis.

The interaction of cultivar-inoculation timing was significant for both FDK and DON in all 3 years (Table 2). Inspection of Figure 1 suggests that the magnitude of the interaction was largest in 2007, smallest in 2006, and intermediate in 2005 (Fig. 1). In 2005, one cultivar (NC-Neuse) had higher FDK and DON from 10-daa inoculation than from 0-daa inoculation (Fig. 1A and B), whereas in 2006, all cultivars had lower FDK and DON resulting from 10-daa inoculations than from 0-daa inoculations (Fig. 1C and D). In 2007, three of the seven cultivars had higher FDK and DON levels from 10-daa than from 0-daa inoculations (Fig. 1E and F). There was no pattern across years in which cultivars or maturities accounted for the interaction.

Duration of post-anthesis moisture had an impact on FDK and DON in 2 of the 3 years (Table 3 ). In 2005, misting duration had no impact on FDK or DON. In 2006, the two longest durations of post-anthesis mist were associated with higher levels of FDK in spikes inoculated at 0 or 10 daa but not in those inoculated at 20 daa (Table 3). In 2007, the two longest durations of post-anthesis mist were associated with FDK higher than that found in nonmisted spikes only for infections at anthesis. In 2006 and 2007, increasing durations of post-anthesis misting were generally associated with higher DON concentrations for all inoculation treatments, although in some cases the difference was only significant for 0 versus 20 or 0 versus 30 days of misting (Table 3 ).

Effects on kernel infection. The Komada's medium assay of percent infected kernels in the 2007 samples indicated that mean percentages of kernels infected with $F$. graminearum were approximately the same across all three inoculation timings (Tables 2 and 3). These percentages were significantly higher than in the noninoculated samples (Table 3). Longer durations of postanthesis mist were associated with increasing percentages of kernel infection in the inoculated treatments (Table 3).

Relationship between FDK and DON. Correlation analysis revealed that the magnitude of the association between FDK and DON varied across levels of the experimental factors and among years (Table 4). FDK and DON were positively correlated for more inoculation date-misting duration combinations in 2005, the lower-disease year (Table 3), than in 2006 or 2007, the higherdisease years. In both 2006 and 2007, FDK and DON were not significantly correlated for most combinations (Table 4). The only combination for which FDK and DON were positively correlated in all 3 years was 10 -daa inoculation and 10-daa misting.
FDK-DON correlation tended to be stronger for lower-daa levels of both inoculation and misting (Table 4). In 2 of 3 years (2005 and 2006), the FDK-DON correlation was stronger for 0and 10-daa inoculations than for 20-daa inoculations (Table 4). In 2007 , the year with greater variability of anthesis timing, the correlation was equally strong for all three inoculation timings. In 2005 and 2006, FDK-DON correlation was stronger for 0-daa misting than for 30-daa misting whereas, in 2007, only 10- and 30-daa misting produced significant correlation.

LFHD. The estimated proportion of individual observations meeting the LFHD criteria (FDK $\leq 4.0 \%$, DON $\geq 2 \mu \mathrm{g} \mathrm{g}^{-1}$ ) was higher in 2007 than in either 2005 or 2006 (41, 14, and 19\%, respectively) (Table 4). There was only one LFHD observation in 2008 (data not shown). Inspection of three-replicate means of each treatment combination (cultivar-inoculation date-mist duration) indicated a difference among the years in the proportion of LFHD means (Fig. 2).

In 2007, the high-LFHD year, the interaction of mist durationinoculation date was significantly associated with LFHD observations (Table 5) $(P<0.0001)$, although the simple effects of mist duration and inoculation date were not. The tests of simple effects within the mist duration-inoculation date interaction (tests of effect slices in PROC GLIMMIX) indicated that some inoculation timings were significantly associated with LFHD for mist duration $>0$ daa, and some mist durations were significantly associated with LFHD for inoculation dates $>0$ daa (Table 5). In other words, inoculation timing had no effect on LFHD unless mist was applied, and mist duration had no effect on LFHD unless inoculation was post-anthesis.

The LFHD proportion was estimated for each combination of inoculation date and mist duration in each year (Table 4). In 2005 and 2006, many inoculation-misting combinations generated estimated LFHD proportions whose confidence intervals included zero. In 2006, the highest proportion of LFHD observations was found in plots inoculated at 10 daa and misted 30 daa. In 2007, the inoculation-misting combinations with the highest LFHD scores were those inoculated and misted 10 daa or inoculated and misted 20 daa, whereas the conditions generating the fewest LFHD observations involved inoculation at 0 or 10 daa followed by 20- or 30-daa misting (Table 4).

Common to all 3 years was that FDK and DON were significantly correlated for 10-daa inoculated and misted plots (Table 4). This treatment combination was also one of two giving rise to the highest level of LFHD in 2007, the high-LFHD year.

\section{DISCUSSION}

The period of maximum susceptibility to $G$. zeae under our experimental conditions included anthesis and a limited time after it. In 3 of 4 years, infections at 10 daa produced less FDK than 0daa infections. In the fourth year (2007), the timing of anthesis was more variable due to SBWMV, and possibly to cold temperatures as well. DON levels were as high from 10-daa infections as from 0-daa infections in 2 years but lower in two other years. Although it was outside the period of maximum host susceptibility, the 20-daa inoculated treatment had percentages of infected kernels not significantly different from those resulting from inoculations at 0 and 10 daa. This suggests that, although Fusarium spp. did spread within 20-daa-inoculated spikes that became infected, the pathogen had limited ability to colonize kernels and grow to the extent necessary to shrivel grain and produce DON. Taken together, these data support the conclusion that $\approx 10$ days or slightly less following mid-anthesis is the most important period for infection of wheat by G. zeae in North Carolina. Ten days after wheat anthesis corresponds to the end of kernel differentiation and the beginning of grain fill (32). Our results suggest that novel control strategies that rely on pathogen incapacitation, such as inhibition of $G$. zeae spore germination, 
must take into account a period of host susceptibility that extends beyond anthesis.

Further, even in situations when variability of anthesis timing is putatively of "normal" duration, problematic levels of DON can apparently be caused by infections occurring as late as 10 daa if there is extended moisture. In 2006, 10-daa infections caused mean DON levels $>2 \mu \mathrm{g} \mathrm{g}^{-1}$ when post-anthesis misting of 20 or 30 days was applied. Increasing durations of moisture tended to increase DON levels for inoculations at 0 and 10 daa in 2 of the 3 years, a somewhat different finding from that of Lacey et al. (12), who observed that post-anthesis moisture had the greatest effect on DON levels when wheat was inoculated at 0 daa. In 2008, 10-daa infections produced mean DON levels $>2 \mu \mathrm{g} \mathrm{g}^{-1}$ only when mist was applied for 14 daa. This finding that longer durations of post-anthesis moisture were associated with higher DON levels is consistent with our other reported results (3).

Although confirmation from additional years would be needed, the 2007 results suggest that longer moisture durations facilitate spread of late infections within spikes, leading to higher percentages of infected kernels and higher DON levels, without a concomitant increase in FDK. For 10- and 20-daa inoculations, FDK levels for 20- and 30-daa misted treatments were not significantly higher than those misted more briefly, but DON levels and percent infected kernels were higher. Fungal spread at this later spike development stage is likely enhanced by increasing water activity in spike tissues (10); however, the physiology of more-
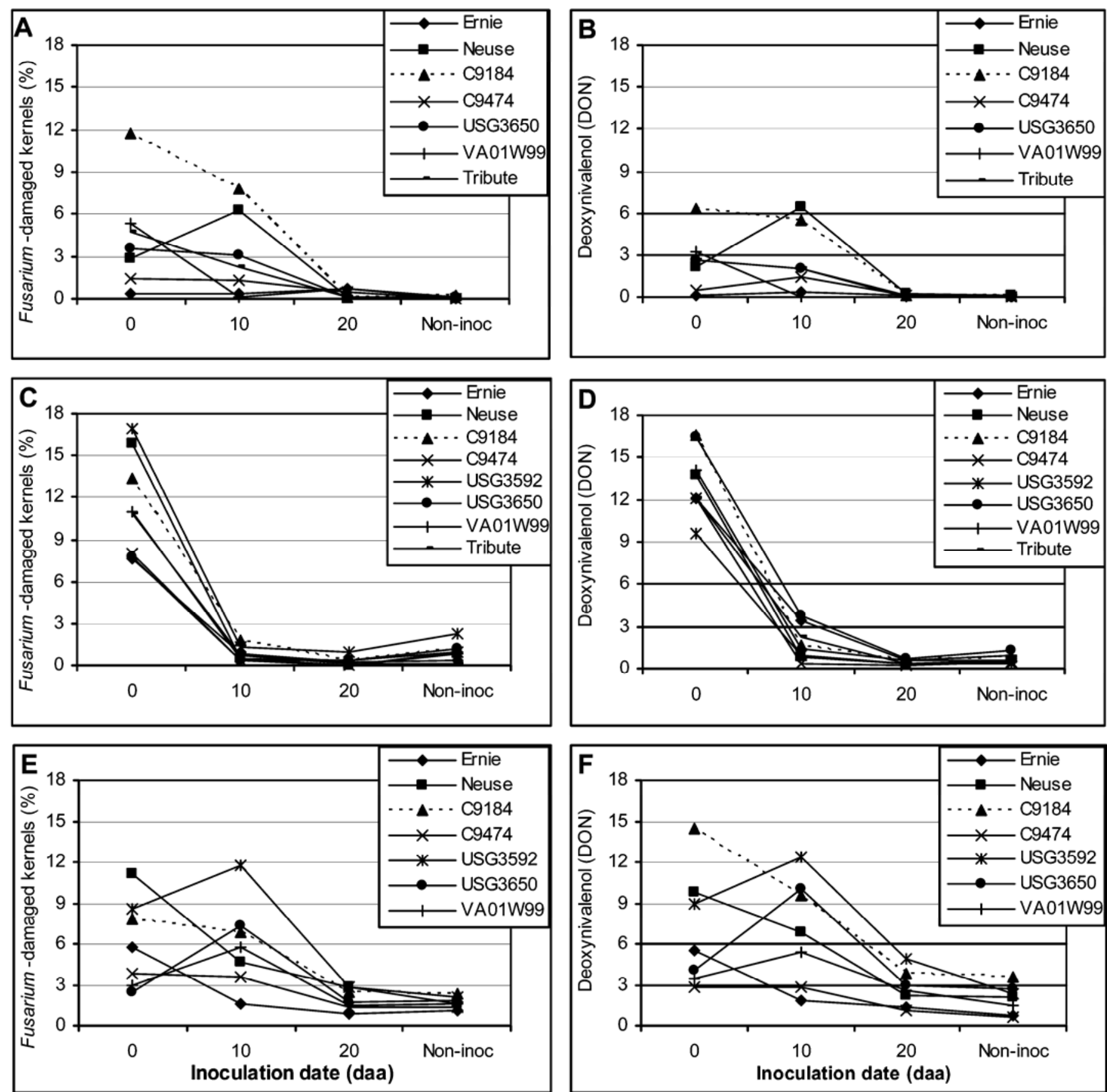

Fig. 1. Cultivar responses to spray inoculation with Fusarium graminearum macroconidia at 0,10 (watery-ripe stage), or 20 (late-milk stage) days after anthesis (daa), and noninoculation, in field plots of winter wheat cultivars at Kinston, NC. Fusarium-damaged kernels for A, 2005; C, 2006; and E, 2007 and deoxynivalenol (DON) for B, 2005; D, 2006; and F, 2007. Data points are means across post-anthesis moisture durations (0, 10, 20, or 30 days); all treatments had three replicates. 
developed kernels makes it more difficult for the fungus to colonize and shrivel them than with an earlier infection $(9,28)$.

In 2007, when SBWMV caused greater within-crop variability in anthesis timing, mean FDK and DON from 10-daa infections were the same as from 0-daa infections, possibly indicating that the period of crop susceptibility to G. zeae infection was widened. In some plots, some plants had only recently finished flowering when the 10-daa inoculations were made and thus were infected at $<10$ daa. On average, however, our observations indicated that the 10-daa treatments were inoculated post-anthesis in 2007, and the 20-daa treatments certainly were as well. As in 2006, application of post-anthesis misting tended to increase DON levels for all infection timings in 2007. The 20-daa inoculations in 2007 were clearly past even the extended period of host susceptibility, and also had problematic DON levels when misted for 20 or 30 daa. In summary, moist conditions during grain fill tended to enhance the severity of FDK and DON even for infections occurring after the period of host susceptibility.

The periodic appearance of asymptomatic grain with unacceptable DON levels has called for an explanation, although the irregular occurrence of this phenomenon makes it difficult to study under natural conditions. Our study utilized artificial inoculation and irrigation. However, in apparent similarity to the natural infrequency of the LFHD phenomenon, 3 years with low to moderate frequency of LFHD $(2005,2006$, and 2008) and 1 year with a high frequency of LFHD (2007) were observed. In 2006 and 2007, the highest frequencies of LFHD $(\geq 60 \%$ of observations for a given treatment) were from inoculations at 10 or 20 daa. The 2006 and 2007 data support the conclusion that LFHD is significantly associated with late $(>0$-daa) infections. Thus, in commercial fields where infections result from natural inoculum, asymptomatic grain with high DON may be more likely if conditions at anthesis are not conducive to FHB but anthesis is then followed fairly closely (i.e., within 1 to
2 weeks) by a rainy period that triggers Fusarium ascospore release.

In this experiment, 2007 was the only year with a large proportion of LFHD observations, and it was also a year with higherthan-normal variability in anthesis timing. It is possible that a high LFHD frequency is associated with high variability in anthesis timing within a field or crop. An experiment currently in progress will help answer this question. Perhaps if infection occurs late relative to overall crop physiology, whether it is in a spike whose flowering is delayed by environmental conditions or a spike that has already finished flowering, the life cycle of the Fusarium fungus is shortened, such that colonization of kernels is reduced relative to DON production.

We examined temperature records for the 3 years and found no indication that temperature differences in the post-anthesis period extended the period of susceptibility in 2007. Mean daily average temperatures (taking into account all temperature measurements for each day) were $5.6^{\circ} \mathrm{C}$ lower in 2006 than in 2007 for the week of inoculation but $\approx 4^{\circ} \mathrm{C}$ lower in 2007 than in 2006 for the subsequent 14-day period, after which time temperatures were similar in the 2 years. In 2005, temperatures for each of those time periods were intermediate between those in 2006 and those in 2007. In all 3 years, daily minimum temperatures during the 2 weeks following anthesis were often below the 15 to $30^{\circ} \mathrm{C}$ range that is favorable for $G$. zeae infection (31). It is possible that the greater frequency of cold nights in the 14-daa period of 2007 contributed to higher LFHD percentages that year; however, the causal link is not obvious.

Researchers have generally found a high degree of correlation between FDK and DON in wheat; a mean correlation coefficient of $r=0.73$ was calculated in a meta-analysis of 163 studies (23). In studies in Germany (1) and Hungary (15) with corn spawn or debris, natural inoculum, or spray inoculum, researchers found that, although FDK and DON were strongly correlated $(r=0.96$

TABLE 4. Correlation between Fusarium-damaged kernels (FDK) and deoxynivalenol (DON) and estimated proportion of "low-FDK, high-DON" (LFHD) observations for each combination of inoculation date (Inoc) and mist duration (Mist) in two low-LFHD years (2005 and 2006) and a high-LFHD year (2007) of a field experiment with Fusarium head blight at Kinston, NC

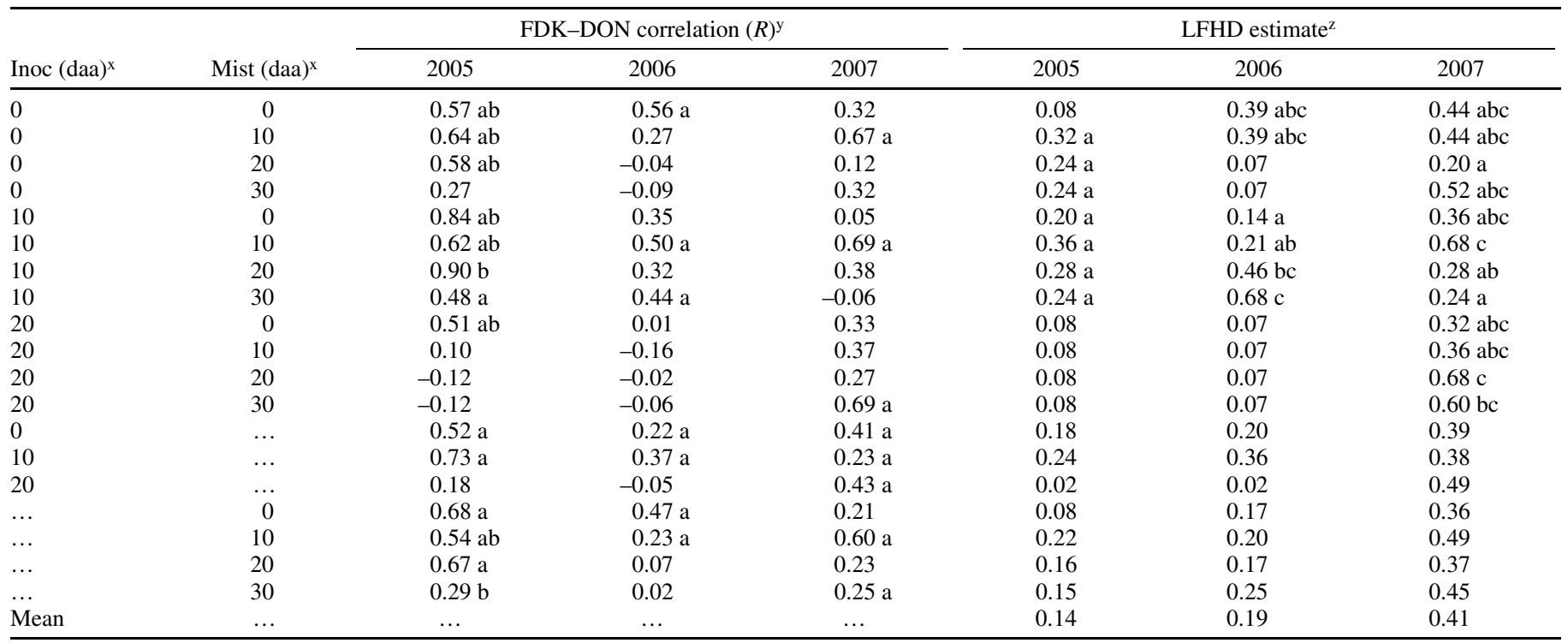

${ }^{\mathrm{x}}$ Days after anthesis (daa): 10 and 20 daa = watery-ripe and late-milk stages, respectively.

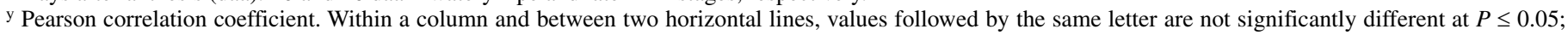
confidence intervals of observations without letters included 0 .

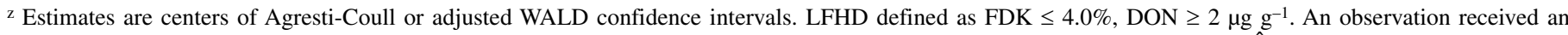
LFHD score of 1 if it met those criteria and 0 if it did not. LFHD estimates were calculated with the adjusted Wald formula $\hat{p}_{\text {adj.Wald }}=[\#($ LFHD $=1)+2] /$ $[\#($ LFHD $=0$ or 1$)]+4=[S+2] /[N+4]$. Within a column, two scores followed by the same letter had overlapping $95 \%$ confidence intervals for the estimated

adjusted Wald mean proportion. $\hat{p}_{\text {adj.Wald }} \pm 1.96 \sqrt{\frac{\hat{p}_{\text {adj.Wald }}\left(1-\hat{p}_{\text {adj.Wald }}\right)}{N+4}}$. Confidence intervals of observations without letters included 0 . 

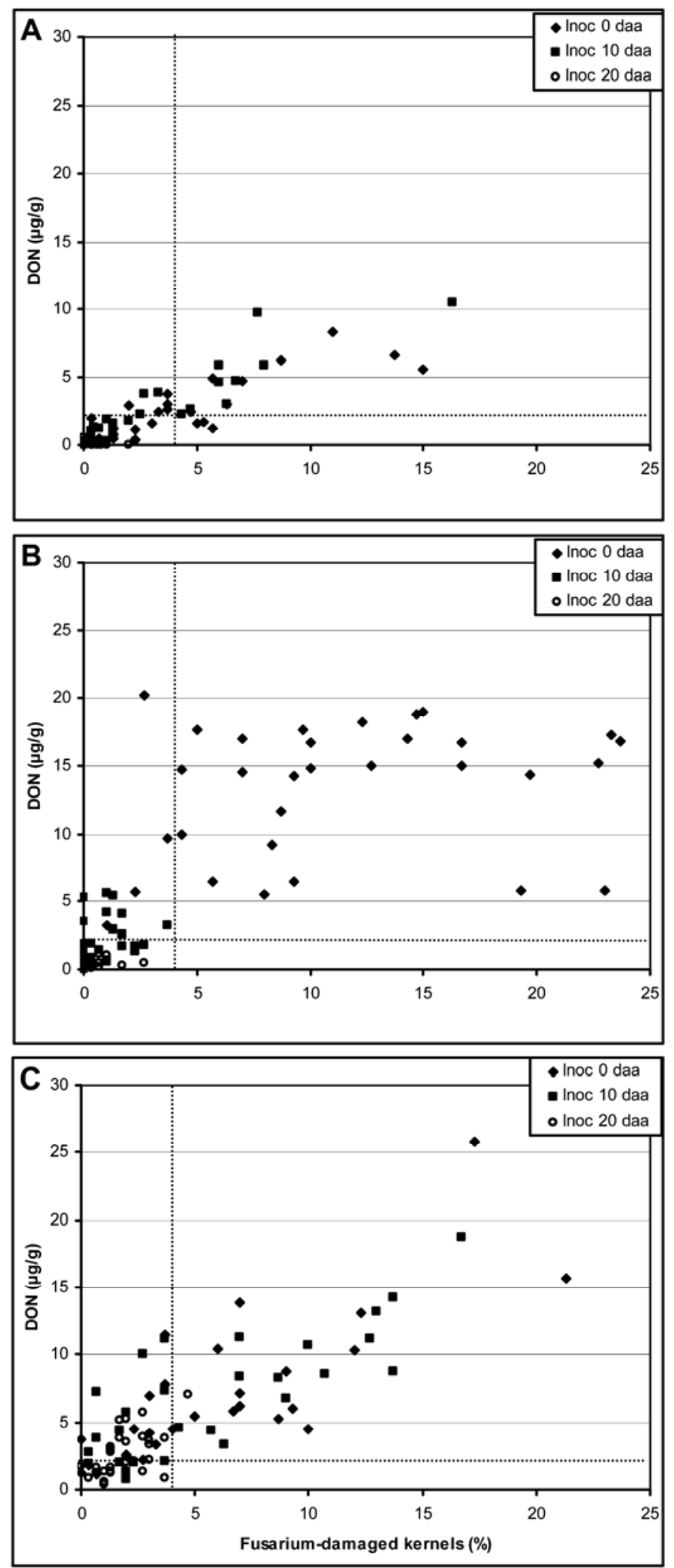

Fig. 2. Fusarium-damaged kernels (FDK) plotted against deoxynivalenol (DON) in grain from field plots of winter wheat cultivars inoculated with Fusarium graminearum macroconidia at 0,10 (watery-ripe stage), or 20 (latemilk stage) days after anthesis (daa) at Kinston, NC in A, 2005; B, 2006; and C, 2007. In the 3 years, seven, eight, and seven cultivars, respectively, were planted. Observations to the left of dotted vertical line at 4\% FDK and above the dotted horizontal line for DON at $2 \mu \mathrm{g} \mathrm{g}^{-1}$ were classified as "low FDK, high DON." Each data point is the mean of three replicates of a cultivarinoculation date-moisture treatment. Durations of post-anthesis moisture were $0,10,20$, or 30 days. and 0.82 in the two studies, respectively), the DON content of FDK varied by a factor of 10 to 12 among years. A field experiment in Illinois using corn spawn or debris as an inoculum source found lower, although still significant, correlation between FDK and DON in each of 2 years $(r=0.38$ and 0.59$)$ (2). These researchers concluded that FDK is generally predictive of DON but there is year-to-year variability in the slope of the regression line (i.e., in some years, there will be higher DON for a given percentage of FDK than in other years). To that picture, we can add that the correlation is affected by both infection timing and moisture.

Analysis of the correlation between FDK and DON showed that in 2 of 3 years (2005 and 2006), 0- and 10-daa inoculations produced similar and stronger FDK-DON correlation than did 20-daa inoculations. Similarly, in 2 of 3 years (2005 and 2006), misting at 0 to 20 or 0 to 10 daa produced higher correlation than at 30 daa. We conclude that the correlation between kernel damage and DON concentrations becomes weaker under conditions of very late infection or extended post-anthesis moisture. This is consistent with the hypothesis that later infections result in DON production without the extensive kernel colonization that leads to shriveling. Extended misting may have encouraged late secondary infections (i.e., from conidia produced on spikes) in our experiment, because prolonged post-anthesis moisture might promote late primary or secondary infections in natural conditions. Misting may alter the relationship of fungal kernel colonization to DON production, because Fusarium spp. growth and DON production are both affected by water activity $\left(\mathrm{a}_{\mathrm{w}}\right)$, although differentially (10). Misting may leach DON from colonized heads $(4,8)$, although this has not yet been demonstrated. It is possible that, when inoculum levels and environmental conditions are more conducive to disease, infections become established that would not do so under less conducive conditions, disrupting the normal relationship between extent of fungal colonization and amount of DON produced. In any case, environmental influences such as post-anthesis rain that increase the proportion of late infections likely also reduce our ability to predict DON levels by grading grain visually for soundness.

TABLE 5. Tests of effects of mist duration (Mist), inoculation date (Inoc), and cultivar (Cv.) on the probability of a "low-Fusarium-damaged kernels (FDK), high-deoxynivalenol (DON)" (LFHD) observation in a 2007 field experiment on Fusarium head blight infection timing in Kinston, $\mathrm{NC}^{\mathrm{v}}$

\begin{tabular}{lcccccc}
\hline Effects & NDF & DDF & $\begin{array}{c}F \\
\text { value }\end{array}$ & $\begin{array}{c}P \\
\text { value }\end{array}$ & Estimate & $\begin{array}{c}\text { Standard } \\
\text { error }\end{array}$ \\
\hline $\begin{array}{l}\text { Fixed effects } \\
\text { Mist }^{\mathrm{w}}\end{array}$ & 3 & 79.9 & 1.23 & 0.307 & $\ldots$ & $\ldots$ \\
Inoc $^{\mathrm{x}}$ & 2 & 240 & 1.68 & 0.189 & $\ldots$ & $\ldots$ \\
$\quad \begin{array}{l}\text { Mist } \times \text { Inoc } \\
\text { Simple effect }\end{array}$ & 6 & 240 & 4.71 & 0.0001 & $\ldots$ & $\ldots$ \\
$\quad \begin{array}{l}\text { Mist (daa) } \\
0\end{array}$ & & & & & & \\
10 & 2 & 240 & 0.50 & 0.606 & $\ldots$ & $\ldots$ \\
20 & 2 & 240 & 3.23 & 0.041 & $\ldots$ & $\ldots$ \\
30 & 2 & 240 & 7.50 & 0.001 & $\ldots$ & $\ldots$ \\
Inoc (daa) & 2 & 240 & 4.02 & 0.019 & $\ldots$ & $\ldots$ \\
0 & 3 & 240 & 2.21 & 0.092 & $\ldots$ & $\ldots$ \\
10 & 3 & 240 & 4.61 & 0.004 & $\ldots$ & $\ldots$ \\
20 & 3 & 240 & 3.69 & 0.014 & $\ldots$ & $\ldots$ \\
Random effects & & & & & & \\
Cv. ${ }^{\mathrm{z}}$ & $\ldots$ & $\ldots$ & $\ldots$ & $\ldots$ & 0.228 & 0.223 \\
Cv. $\times$ rep(irrig) & $\ldots$ & $\ldots$ & $\ldots$ & $\ldots$ & 0.062 & 0.276 \\
\hline
\end{tabular}

${ }^{v}$ Results of analysis with PROC GLIMMIX. Null hypothesis was no association (i.e., $P \leq 0.05$ indicates the independent variable had a significant positive effect on probability of LFHD observations).

${ }^{\text {w }}$ Mist durations were $0,10,20$, or 30 days after anthesis (daa).

${ }^{\mathrm{x}}$ Inoculations of individual randomly chosen heads were performed at 0,10 , or 20 daa with a spray bottle.

${ }^{y}$ Tests of simple effect for mist duration $\times$ inoculation date.

${ }^{\mathrm{z}}$ Seven cultivars (five moderately resistant and two susceptible). 
Our central conclusion about LFHD is that its likelihood is maximized by specific combinations of late infection and moisture. In 2007, our only high-LFHD year, we observed that inoculation timing had no effect on LFHD unless mist was applied, and mist duration had no effect on LFHD unless inoculation was post-anthesis. Our data suggest that, under natural conditions, the exact timing of LFHD-generating moisture events in relation to anthesis could vary from year to year but watery-ripe and latemilk stages both appear to be vulnerable, if they are combined with what we might call "marginal but permissive" conditions of moisture and temperature.

In 2007, the high-LFHD year, FDK and DON were correlated for 0 - and 10-daa infections receiving 10-daa mist and for 20-daa infections receiving 30-daa mist. High proportions of LFHD also resulted from the treatment inoculated and misted 10 daa, and the treatment inoculated 20 daa and misted 30 daa. In other words, there was some coincidence of treatments with high FDK-DON correlation and those with high proportions of LFHD. For these treatments, mean FDK levels were just over $2 \%$, whereas mean DON levels were well above $2 \mu \mathrm{g} \mathrm{g}^{-1}$. This suggests that many of the observations in these treatments were close to the defined limits for LFHD, because they contributed both to a high degree of FDK-DON correlation and also to the LFHD category. The highest-probability conditions for LFHD were for 10-daa misting and inoculation and 20-daa misting and inoculation. In each case, percent infected seed was the same as for the 0-daa misted treatment for that inoculation date. This suggests that the fungus was able to establish but did not spread as far in the spike as it would have if misting had continued past the inoculation date.

Considering the 2006 and 2007 data, we conclude that the most favorable conditions for LFHD grain are marginal but not nonconducive to FHB. In 2006, when anthesis was clearly the most favorable timing for infection and disease development, LFHD was maximized by infection at watery-ripe stage with subsequent misting; by late-milk stage, conditions were nonconducive. In 2007, when both 0 and 10 daa were favorable for infection and disease, LFHD conditions were at watery-ripe stage without subsequent moisture or at late-milk stage with or without subsequent misting.

In summary, the period of maximum susceptibility of winter wheat to G. zeae infection normally extends to $\approx 10$ daa in North Carolina. This suggests that a fungicide residual activity of 10 to 14 days should be sufficient to cover the high-vulnerability time period, assuming optimal application at early anthesis. However, extended post-anthesis rain should be expected to elevate FDK and DON even in late-infected wheat crops. Periods of rain soon after anthesis are likely conducive to the low-symptom, highDON scenario, which is associated with certain combinations of late infection and prolonged moisture that create conditions that are marginal but still permissive of $G$. zeae infection and establishment. The LFHD scenario may also be associated with conditions that create greater variability in anthesis timing, thus extending the normal window of susceptibility.

\section{ACKNOWLEDGMENTS}

We thank R. Littell for statistical advice; D. Fulbright, P. Hart, and C. Medina-Mora, Michigan State University Regional Diagnostic Center for FHB, and Y. Dong, University of Minnesota, for DON testing services; and E. Duren, M. Fountain, R. Parks, J. Patton-Özkurt, and the staff of Cunningham Research and Extension Center for excellent technical assistance.

\section{LITERATURE CITED}

1. Beyer, M., Klix, M. B., and Verreet, J.-A. 2007. Estimating mycotoxin contents of Fusarium-damaged winter wheat kernels. Int. J. Food Microbiol. 119:153-158.

2. Bonin, C. M., and Kolb, F. L. 2009. Resistance to Fusarium head blight and kernel damage in a winter wheat recombinant inbred line population. Crop Sci. 49:1304-1312.

3. Cowger, C., Patton-Özkurt, J., Brown-Guedira, G., and Perugini, L. 2009. Post-anthesis moisture increased Fusarium head blight and deoxynivalenol levels in North Carolina winter wheat field experiment. Phytopathology 99:320-327.

4. Culler, M. D., Miller-Garvin, J. E., and Dill-Macky, R. 2007. Effect of extended irrigation and host resistance on deoxynivalenol accumulation in Fusarium-infected wheat. Plant Dis. 91:1464-1472.

5. Del Ponte, E. M., Fernandes, J. M. C., and Bergstrom, G. C. 2003. Fusarium head blight and deoxynivalenol accumulation in wheat inoculated at developmental stages from flowering through grain maturation. Pages 129-132 in: Proc. Natl. Fusarium Head Blight Forum. S. M. Canty, J. Lewis, and R. W. Wards, eds. Michigan State University.

6. Del Ponte, E. M., Fernandes, J. M. C., and Bergstrom, G. C. 2007. Influence of growth stage on Fusarium head blight and deoxynivalenol production in wheat. J. Phytopathol. 155:577-581.

7. Francl, L., Shaner, G., Bergstrom, G. C., Gilbert, J., Pedersen, W., DillMacky, R., Sweets, L., Corwin, B., Jin, Y., Gallenberg, D., and Wiersma, J. 1999. Daily inoculum levels of Gibberella zeae on wheat spikes. Plant Dis. 83:662-666.

8. Gautam, P., and Dill-Macky, R. 2008. Impact of extended periods of mistirrigation on deoxynivalenol accumulation in Fusarium-infected wheat. Page 21 in: Proc. Natl. Fusarium Head Blight Forum. S. M. Canty, E. Walton, A. Clark, D. Ellis, J. Mundell, and D. A. Van Sanfords, eds. University of Kentucky.

9. Hart, L. P., Pestka, J. J., and Liu, M. T. 1984. Effect of kernel development and wet periods on production of deoxynivalenol in wheat infected with Gibberella zeae. Phytopathology 74:1415-1418.

10. Hope, R., Aldred, D., and Magan, N. 2005. Comparison of environmental profiles for growth and deoxynivalenol production of Fusarium culmorum and F. graminearum on wheat grain. Lett. Appl. Microbiol. 40:295-300.

11. Komada, H. 1976. A new selective medium for isolating Fusarium from natural soil. Proc. Am. Phytopathol. Soc. 3:221.

12. Lacey, J., Bateman, G. L., and Mirocha, C. J. 1999. Effects of infection time and moisture on development of ear blight and deoxynivalenol production by Fusarium spp. in wheat. Ann. Appl. Biol. 134:277-283.

13. McMullen, M., Jones, R., and Gallenberg, D. 1997. Scab of wheat and barley: A re-emerging disease of devastating impact. Plant Dis. 81:13401348.

14. Mesterhazy, A. 1995. Types and components of resistance to Fusarium head blight of wheat. Plant Breed. 114:377-386.

15. Mesterhazy, A. 2002. Role of deoxynivalenol in aggressiveness of Fusarium graminearum and F. culmorum and in resistance to Fusarium head blight. Eur. J. Plant Pathol. 108:675-684.

16. Miedaner, T., Heinrich, N., Schneider, B., Oettler, G., Rohde, S., and Rabenstein, F. 2004. Estimation of deoxynivalenol (DON) content by symptom rating and exoantigen content for resistance selection in wheat and triticale. Euphytica 139:123-132.

17. Murphy, J. P., and Navarro, R. 2001. Uniform Southern Soft Red Winter Wheat Fusarium Head Blight Screening Nursery, 2001 Nursery Report. North Carolina State University, Raleigh.

18. Murphy, J. P., Navarro, R., and Srnic, G. 2000. Uniform Southern Soft Red Winter Wheat Fusarium Head Blight Screening Nursery, 2000 Nursery Report. North Carolina State University, Raleigh.

19. Murphy, J. P., Navarro, R. A., and Van Sanford, D. A. 2002. Uniform Southern Soft Red Winter Wheat Fusarium Head Blight Screening Nursery, 2002 Nursery Report. North Carolina State University, Raleigh.

20. Murphy, J. P., Navarro, R. A., and Van Sanford, D. A. 2003. Uniform Southern Soft Red Winter Wheat Fusarium Head Blight Screening Nursery, 2003 Nursery Report. North Carolina State University, Raleigh.

21. Parry, D. W., Jenkinson, P., and McLeod, L. 1995. Fusarium ear blight (scab) in small grain cereals-a review. Plant Pathol. 44:207-238.

22. Pate, M. H., Sullins, R. D., and Faga, B. A. 2003. Impact of increased DON levels on the milling and baking industry. Pages 1 in: Proc. Natl. Fusarium Head Blight Forum. S. M. Canty, J. Lewis, L. Siler, and R. W. Wards, eds. Michigan State University.

23. Paul, P. A., Lipps, P. E., and Madden, L. V. 2005. Relationship between visual estimates of Fusarium head blight intensity and deoxynivalenol accumulation in harvested wheat grain: A meta-analysis. Phytopathology 95:1225-1236.

24. Saxton, A. M. 1998. A macro for converting mean separation output to letter groupings in Proc Mixed. Pages 1243-1246 in: Proc. 23rd SAS Users Group International. SAS Institute, Cary, NC.

25. Schmale, D. G., III, and Bergstrom, G. C. 2003. Fusarium head blight. The Plant Health Instructor. DOI:10.1094/PHI-I-2003-0612-01.

26. Schroeder, H. W., and Christensen, J. J. 1963. Factors affecting resistance of wheat to scab caused by Gibberella zeae. Phytopathology 53:831-838.

27. Shaner, G., and Buechley, G. 2003. Relation between head blight and 
grain quality in the Indiana FHB epidemic of 2003. Pages 178-181 in: Proc. Natl. Fusarium Head Blight Forum. S. M. Canty, J. Lewis, and R. W. Wards, eds. Michigan State University.

28. Stack, R. W. 2000. Return of an old problem: Fusarium head blight of small grains. The Plant Health Instructor. DOI:10.1094/PHP-2000-062201-RV.

29. Steel, R. G. D., Torrie, J. H., and Dickey, D. A. 1997. Principles and Procedures of Statistics: A Biomedical Approach, 3rd ed. McGraw-Hill, New York.

30. Sutton, A. L., and Cowger, C. 2004. The Fusarium head blight epidemic of 2003 in the southeastern United States. Special Report, United States Wheat and Barley Scab Initiative. http://scabusa.org/pdfs/sedon_report_11-04.pdf.

31. Tschanz, A. T., Horst, R. K., and Nelson, P. E. 1976. The effect of environment on sexual reproduction of Gibberella zeae. Mycologia $68: 327-340$

32. Wan, Y., Poole, R. L., Huttly, A. K., Toscano-Underwood, C., Feeney, K., Welham, S., Gooding, M. J., Mills, C., Edwards, K. J., Shewry, P. R., and Mitchell, R. A. C. 2008. Transcriptome analysis of grain development in hexaploid wheat. BMC Genomics 9:121. 